\title{
Biology and Philosophy. III. About Mongrels and How to Shoot down a Crab from a Tree
}

\author{
Juan S. Gómez-Jeria
}

\begin{abstract}
The history of mating between Homo sapiens, Neanderthals, Denisovans and one or more unknown hominids is presented. It is stated that the Sub-Saharan populations are the only ones deserving to be called Homo sapiens sapiens. The remaining population of the world is composed by Homo sapiens with different percentage of DNA coming from Neanderthals, Denisovans and/or possibly other hominids. It is suggested that this mixture produced individuals able to build great civilizations. Finally some comments about an incorrect comparison between Athenians and current people are presented.
\end{abstract}

Index Terms - Homo sapiens, Neanderthal, Denisovan, genetic hybrids, human history, Ancient Greece, genetic engineering, Classical Athens, Sparta, eugenics.

\section{INTRODUCTION}

'He who thus considers things in their first growth and origin, whether a state or anything else, will obtain the clearest view of them', says Aristotle in his Politics. Concerning the historical developments leading to the actual situation of Homo sapiens sapiens on Earth, Aristotle's suggestion should serve as a guiding principle. Nevertheless, there are some fundamental problems obstructing the application of this approach to this area of knowledge. One is related to the fact that some statements have become the communis opinio of all the specialists in the field only because either no fact appears to contradict them or nobody questions them. The other is, from a strictly scientific point of view, quite disturbing. It consists in a conscious and silent refusal to raise all the possible scientific questions that arise naturally from the research and propose all the possible tentative scientific answers to them. Some reasons for this refusal might be, for example, fear of what is behind the doors that these questions may open, personal interests, lack of scientific motivation, keeping safe one's academic reputation and money for research, etc. This text offers some personal thoughts about human evolution, presenting some questions that must be asked but are not and providing provisional provocative conclusions, a task that almost all specialists discretely overlook. The hypotheses presented here need factual verification before stating that they may be momentarily or definitively true.

Because I do not know the way to the market or to the public place I can present these provocative hypotheses. A last word: Abandon hope all ye who enter here.

Juan S. Gómez-Jeria, Faculty of Sciences, University of Chile, Santiago, RM, Chile

\section{Human EVOLUTiON}

It seems that the statement that 'Africa is where we evolved and where we have spent the most part of our time' is true. Let us consider a human phylogenetic tree. When our knowledge about human evolution was at its beginning, this tree had only a temporal dimension. Now, it also has a spatial dimension to include the geographical loci of the new species of the genus Homo (Neanderthals, Denisovans, Homo floresiensis, the dispersion of Homo erectus, etc. ${ }^{[1]}$.

The phylogenetic tree of the genus Homo has changed, sometimes dramatically, with most of these discoveries. In theory, the problem of this phylogenetic tree can be summarized as follows: let $\mathrm{N}$ be the total number of Homo fossils that can be theoretically discovered. Let us suppose that we finally have $\mathrm{n}$ fossils in our hands. With $\mathrm{n}$ fossils we may state one or more conditions to build the best possible phylogenetic tree. If this tree is correct or not is a different issue. Now, as the value of $\mathrm{N}$ is not known, we have no way to know if we have acquired all possible fossils. Therefore, any set of hypotheses that can be stated about the history of these $\mathrm{n}$ fossils can be put forth with the understanding that maybe new physical evidence will modify or even destroy them. But what is clear now is that human evolution is a much more varied and complex process than believed.

In the first part I will use (or abuse) the phylogenetic tree to present a confrontational hypothesis concerning the possible reason(s) leading to the cultural products of the two recognized subspecies of Homo sapiens. They are pure speculation, but a speculation based on what we actually know. This will be useful to show the nature of the distortion leading from a scientific hypothesis to a 'political truth'. The second part consists in some thoughts about a paper by Gerald Crabtree ${ }^{[2]}$.

\section{THE PARTICIPANTS}

When I was thinking how to make the correct understanding of this text easier without repeating parts of part 2 of this series, I read David Reich's book 'Who we are and how we got here ' [3]. It is a 'must read'. I will use here some of the figures of that book with permission. Let us remember that these taxa were coexisting for about 300,000 years (Homo naledi, Homo floresiensis, Denisovans, Neanderthals, anatomically modern humans and even Homo erectus). Now let us consider the following kinds of 'pure' specimens considered here ('pure' is a relative term).

1. Homo erectus descended probably from the Australopithecines in East Africa about 2.6 mya (Lake Turkana and Olduvai Gorge). From there it migrated by 2.0 
mya to the Old World (Dmanisi in Georgia, Sangiran in Central Java, Trinil in East Java and Zhoukoudian and Shaanxi in China). Paleoanthropologists still quarrel over the classification of the Homo erectus fossils. Recent excavations at Kalinga in the Cagayan Valley of northern Luzon (Philippines) show hominin activity dated to about 709,000 years ago ${ }^{[4]}$. Known varieties of Asian $H$. erectus were possibly extinct by 500,000 years ago (surely by 143,000 years ago as the case of Homo erectus soloensis). Homo erectus existed for well over one million years and perhaps over two million years. During this it is highly probable that they mated with members of other species (Neanderthals, archaic Homo sapiens). Maybe a Homo erectus is the prime suspect in the case of the Andamanese genome ${ }^{[5]}$. Anyway, it seems that Homo erectus inherited from Australopithecines the fabrication of stone tools (this because the oldest known Homo fossil is 2.8 million years old compared to the 3.3 million year age of the oldest stone tools ${ }^{[6]}$ ).

2. Homo sapiens neanderthalensis (Hsn, Neanderthals ${ }^{[7]}$ ). Capra et al. stated that "Neanderthals are believed to have lived out of Africa long enough to adapt to the climatic, dietary and pathogenic landscapes found at higher latitudes". In their work they conclude that "Neanderthal alleles together explained a significant fraction of the variation in risk for depression and skin lesions resulting from sun exposure (actinic keratosis), and individual Neanderthal alleles were significantly associated with specific human phenotypes, including hypercoagulation and tobacco use" ${ }^{[8]}$. In a recent paper, Dediu and Levinson summarized what we know about Neanderthals ${ }^{[9]}$ : 'they did adapt their diet and technology to local conditions', 'had advanced leather processing technology', 'using stone and bone awls (such as found in the Grotte du Renne) as sewing aids', 'bitter medicinal herbs were consumed', etc. The question is that that they have nothing to envy us. It has even been suggested that our ancestors copied from Neanderthals the use of lissoirs. The Neanderthal cultural products were mentioned in the first and second parts of this series ${ }^{[10,11]}$. We shall add the decorated raven bone from the Zaskalnaya VI (Kolosovskaya) Neanderthal site, Crimea ${ }^{[12]}$. And, almost beyond doubt, they had language ${ }^{[9]}$. The site of Poggetti Vecchi (Italy), dated to 170,000 years ago, provides evidence of the processing and use of wood by early Neanderthals, showing their ability to use fire in tool making from very tough wood ${ }^{[13]}$. And we cannot forget the set of eight wooden throwing spears from the Paleolithic that were excavated between 1994 and 1998 in the lignite mine in Schöningen Germany ${ }^{[14]}$. They are between 337,000 and 300,000 years old.

3. Homo sapiens sapiens (Hss). The anatomically modern Homo sapiens and their descendants belong to this group. Their direct descendants are the present central and southern African populations. The accepted idea that the earliest fossils of perceptibly modern Homo sapiens were from Omo Kibish (Ethiopia), around 200,000 years ago was shaken by the discovery, at Adrar Ighud (Morocco), of specimens of Homo sapiens dated to over 300,000 years and of Homo naledi in South Africa dated between about 236,000 and
335,000 years ago. Interestingly, and as far as I know, this group does not show any trace of very ancient cultural products similar to the Neanderthal activity in the Bruniquel cave. For this statement I read some books dealing with the history of Africa ${ }^{[15-17]}$

4. Denisovans ${ }^{[18,19] . ~ D e n i s o v a n s ~ w e r e ~ a c t u a l l y ~ a ~ s i s t e r ~}$ group to the Neanderthals, branching off from the human lineage 600,000 years ago, and diverging from Neanderthals, probably in the Middle East, 200,000 years later. Denisovans overlapped geographically with Neanderthals in the Altai region and possibly elsewhere. Denisovan ancestry is detected in present-day human populations from Oceania, mainland Asia and in Native Americans. For example, the Inuit variant of the TBX15/WARS2 region first came into modern humans from an archaic hominid population, likely related to the Denisovans ${ }^{[20]}$.

\section{MisCEGENATION}

A maxilla and associated dentition of modern humans was discovered at Misliya Cave, Mount Carmel and was dated to 177,000 to 194,000 years ago. This suggests an early dispersal of Homo sapiens outside of Africa circa 220,000 years ago ${ }^{[21]}$. The many out-of-Africa migrations potentially brought early modern humans into the territories of other hominin populations, including the Neanderthals in western Eurasia, and Homo floresiensis and the ancient species Homo erectus in Indonesia ${ }^{[22]}$. The following two figures show the extensive and lasting opportunities for Homo sapiens Neanderthal miscegenation ${ }^{[3]}$.

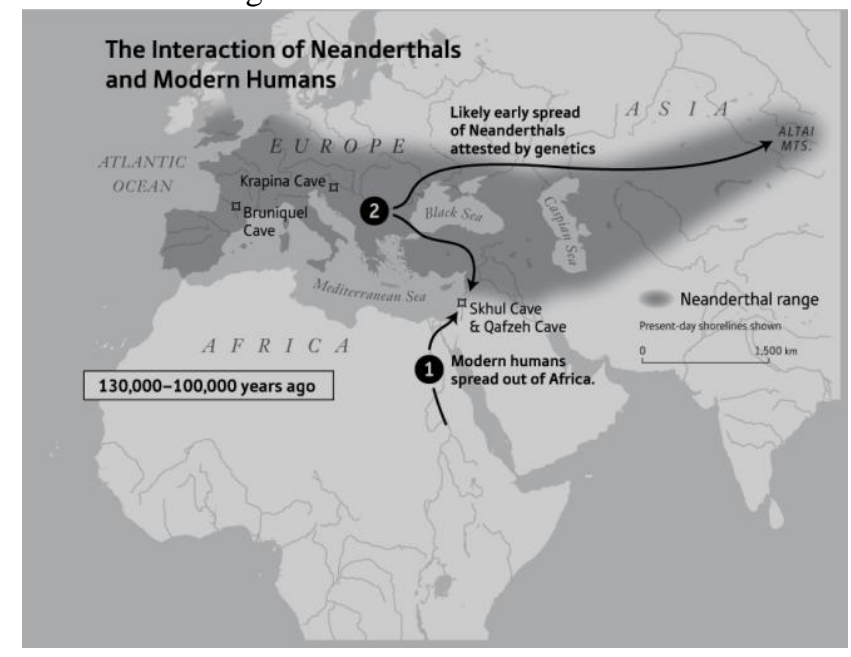

Therefore, the question 'Why were modern humans so successful whereas Denisovans and Neanderthals went extinct?' is totally wrong! It must be replaced by this other: Why were the 'Homo sapiens-with Neanderthal DNA-with Denisovan DNA' so successful whereas 'Denisovans', 'Denisovans with human DNA', 'Neanderthals with human DNA', 'Neanderthals', and other possible mixtures went extinct? 


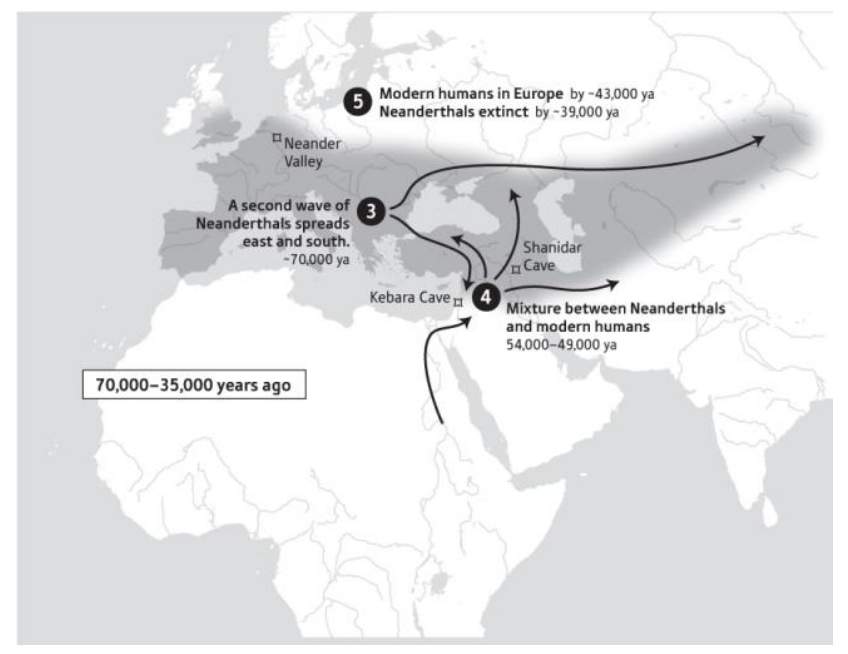

And why did Homo sapiens without any other DNA contribution (i.e., the sub-Saharans) never build civilizations like China, India, Greece, Rome, Persia, Sumer, Babylon, etc., etc.? As such the question is legitimate and demands a scientific answer now. Let us remember that sooner or later these questions reach all readers and surely some of them will suggest and promote the non-scientific and frightening answer to the last question: because one group is superior to the other. The next figures show the contributions of Neanderthal and Denisovan DNA to present-day populations [3]

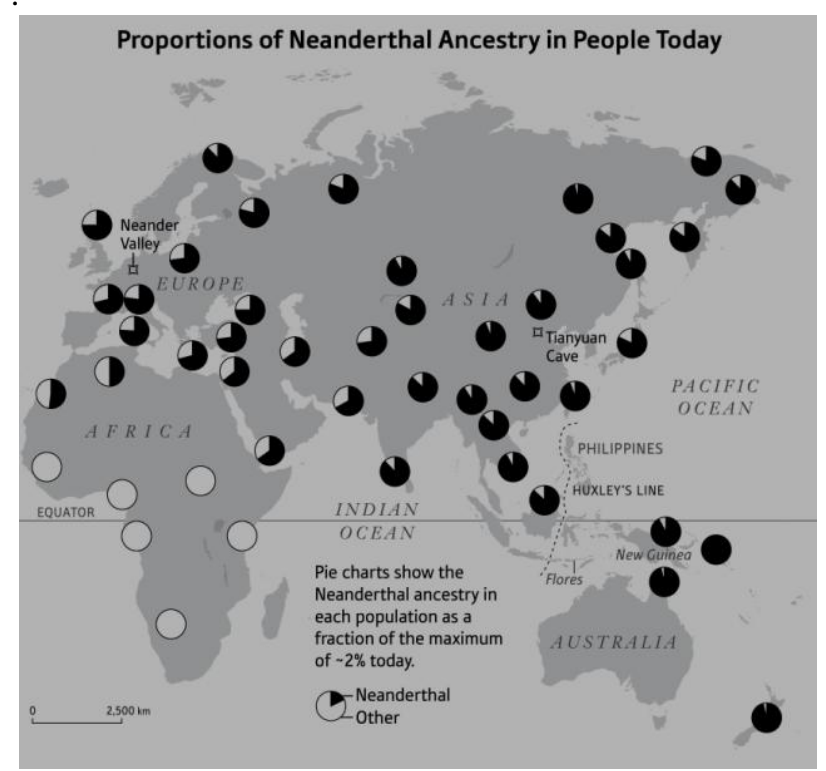

We can see that the only populations having zero Neanderthal and/or Denisovan DNA are the sub-Saharan ones. Formally, they could be the only pure extant Homo sapiens sapiens populations! The above construct allows me to make a prediction. The Pleistocene cave art from Sulawesi (Indonesia) is proof that members of the genus Homo were producing rock art by about $40 \mathrm{kyr}$ ago at opposite ends of the Eurasian Pleistocene ${ }^{[23]}$. But what members were they? I predict that if fossils associated with these paintings or similar ones are found there and DNA can be extracted and analyzed it will correspond to DNA of anatomically modern Homo sapiens but with contributions from Neanderthal/ Denisovan/unknown origin. The argument stating that, because all living descendants of the anatomically modern sapiens that left Africa have DNA with Neanderthal and/or Denisovan contributions, the Sulawesi painters must have similar DNA does not hold. The first reason is that it has not been proved that this statement is true for all people. The second argument states that the fact of leaving Africa does not oblige the travellers to mate with the first foreign population they find (remember that the many populations of hominids were probably separated by very extensive territories at least in Asia). As a provocative conclusion of these lines I think that I must be proud to be (at least) a Homo sapiens sapiens + Neanderthal + Denisovan hybrid.

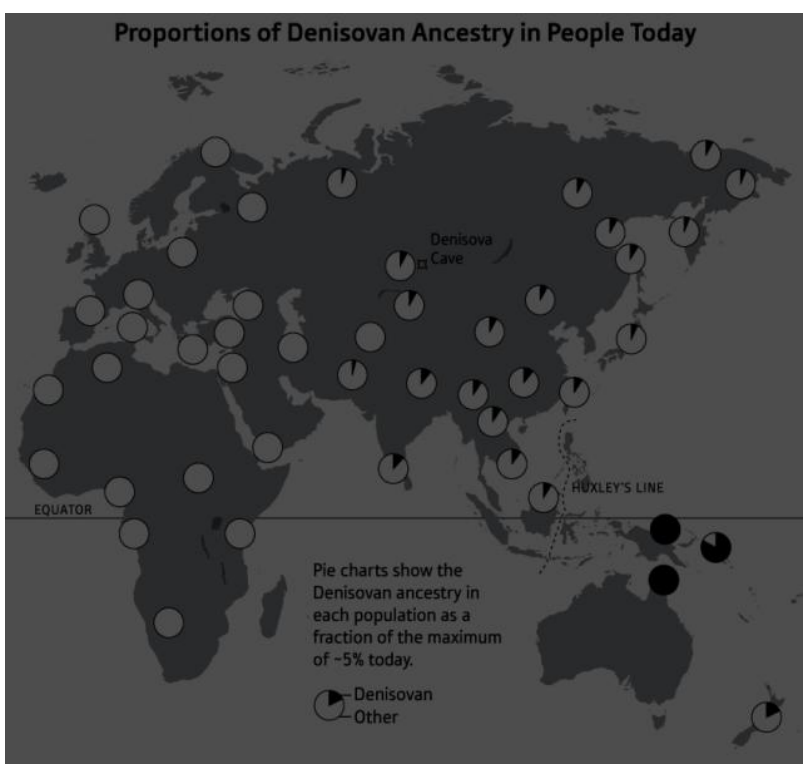

V. How to ShOOT DOWn A CRAB FROM A TREE

A few years ago, Gerald Crabtree stated that "I would wager that if an average citizen from Athens of $1000 \mathrm{BC}$ were to appear suddenly among us, he or she would be among the brightest and most intellectually alive of our colleagues and companions, with a good memory, a broad range of ideas, and a clear-sighted view of important issues. Furthermore, I would guess that he or she would be among the most emotionally stable of our friends and colleagues. I would also make this wager for the ancient inhabitants of Africa, Asia, India, or the Americas, of perhaps 2000-6000 years ago" "2]. Crabtree declared that "the basis for my wager comes from new developments in genetics, anthropology, and neurobiology that make a clear prediction that our intellectual and emotional abilities are genetically surprisingly fragile". It is clear that our intellectual abilities are genetically surprisingly fragile. The question seems to be that this fragility is more accentuated in people who are bright.

The first statement can be decomposed into the following parts:

1. I would wager that if an average citizen from Athens of 1000 BC were to appear suddenly among us... The question to clarify here is the nature of an average citizen living in Athens at that time. We are about two hundred years after the hero Theseus, and Athens seems to begin to expand into the area that had formerly been limited to cemeteries. Unhappily, there is no information about the people inhabiting the city at that time. Moreover, the year 1000 BC is within the Greek 
Dark Ages period. Therefore we must reject this year, assume that we know what Crabtree was trying to say and propose another year. Neither Hesiod and Homer (if he existed) nor Heraclitus and many presocratics can be used as models of an 'average citizen'. On the contrary, they are good examples of genetic enlightenment.

2. He or she would be among the brightest and most intellectually alive of our colleagues and companions... It is difficult to comment on this part because Crabtree does not provide concrete examples of brightest and/or intellectually alive people. And, believe it or not, this is a difficult task.

3. With a good memory, a broad range of ideas. Good memory? No doubt at all because of the lack of tables, cell phones, pendrives, laptops, etc., and books for all. A broad range of ideas? I do not believe this but it would be interesting to have a list of ideas.

4. and a clear-sighted view of important issues. I doubt this. It is only question of reading the biography of Demosthenes or any other Greek politician to appreciate that many of them were short-sighted at very important moments. Probably the only important issue that a Greek of classical Athens among us would notice is the uncontrolled population growth leading sooner or later to a catastrophe we shall regret. And perhaps if he came, not from Athens but from Sparta, he would remind us that they threw criminals, weak, sickly, deformed, or mentally retarded infants into the chasm of Mount Taygetus known as Keadas. And, if we compare Spartans with us, there is no doubt that any indices measuring the biological quality of that population were incredibly better than today's. And if my hypothetical Spartan noticed that we have a branch of science called Genetic Engineering, he would ask us what we are waiting for to use it to improve ourselves physically and mentally.

And, considering that the actual world population is composed by true Homo sapiens and genetic hybrids, the argument of Crabtree seems to suffer from extensional vagueness.

\section{REFERENCES}

[1] Árnason, Ú. A phylogenetic view of the Out of Asia/Eurasia and Out of Africa hypotheses in the light of recent molecular and palaeontological finds. Gene 2017, 627, 473-476.

[2] Crabtree, G. R. Our fragile intellect. Part I. Trends in Genetics 2013, 29, 1-3.

[3] Reich, D. Who we are and how we got here: ancient DNA revolution and the new science of the human past. First edition. ed.; Pantheon Books: New York, 2018; p xxv, 335 pages.

[4] Ingicco, T.; van den Bergh, G. D.; Jago-on, C.; Bahain, J. J.; Chacón, M. G.; Amano, N.; Forestier, H.; King, C.; Manalo, K.; Nomade, S.; Pereira, A.; Reyes, M. C.; Sémah, A. M.; Shao, Q.; Voinchet, P.; Falguères, C.; Albers, P. C. H.; Lising, M.; Lyras, G.; Yurnaldi, D.; Rochette, P.; Bautista, A.; de Vos, J. Earliest known hominin activity in the Philippines by 709 thousand years ago. Nature 2018, 557, 233-237.

[5] Mondal, M.; Casals, F.; Xu, T.; Dall'Olio, G. M.; Pybus, M.; Netea, M. G.; Comas, D.; Laayouni, H.; Li, Q.; Majumder, P. P.; Bertranpetit, J. Genomic analysis of Andamanese provides insights into ancient human migration into Asia and adaptation. Nature Genetics 2016, 48, 1066.

[6] Harmand, S.; Lewis, J. E.; Feibel, C. S.; Lepre, C. J.; Prat, S.; Lenoble, A.; Boës, X.; Quinn, R. L.; Brenet, M.; Arroyo, A.; Taylor, N.; Clément, S.; Daver, G.; Brugal, J.-P.; Leakey, L.; Mortlock, R. A.; Wright, J. D.; Lokorodi, S.; Kirwa, C.; Kent, D. V.; Roche, H. 3.3-million-year-old stone tools from Lomekwi 3, West Turkana, Kenya. Nature 2015, 521, 310.

[7] Meyer, M.; Arsuaga, J.-L.; de Filippo, C.; Nagel, S.; Aximu-Petri, A.; Nickel, B.; Martínez, I.; Gracia, A.; de Castro, J. M. B.; Carbonell, E.; Viola, B.; Kelso, J.; Prüfer, K.; Pääbo, S. Nuclear DNA sequences from the Middle Pleistocene Sima de los Huesos hominins. Nature 2016, 531, 504-507.

[8] Simonti, C. N.; Vernot, B.; Bastarache, L.; Bottinger, E.; Carrell, D. S.; Chisholm, R. L.; Crosslin, D. R.; Hebbring, S. J.; Jarvik, G. P.; Kullo, I. J.; Li, R.; Pathak, J.; Ritchie, M. D.; Roden, D. M.; Verma, S. S. Tromp, G.; Prato, J. D.; Bush, W. S.; Akey, J. M.; Denny, J. C.; Capra, J. A. The phenotypic legacy of admixture between modern humans and Neandertals. Science 2016, 351, 737-741.

[9] Dediu, D.; Levinson, S. C. Neanderthal language revisited: not only us. Current Opinion in Behavioral Sciences 2018, 21, 49-55.

[10] Gómez-Jeria, J. S. Biology and Philosophy. Part I. The Paleolithic. World Journal of Research and Review 2017, 4, 21-28.

[11] Gómez-Jeria, J. S. Biology and Philosophy. Part II. The Upper Paleolithic and the Holocene. World Journal of Research and Review 2017, 4, 42-47.

[12] Majkić, A.; Evans, S.; Stepanchuk, V.; Tsvelykh, A.; d'Errico, F. A decorated raven bone from the Zaskalnaya VI (Kolosovskaya) Neanderthal site, Crimea. PLOS ONE 2017, 12, e0173435.

[13] Aranguren, B.; Revedin, A.; Amico, N.; Cavulli, F.; Giachi, G.; Grimaldi, S.; Macchioni, N.; Santaniello, F. Wooden tools and fire technology in the early Neanderthal site of Poggetti Vecchi (Italy). Proceedings of the National Academy of Sciences 2018, 115, 2054-2059.

[14] Thieme, H. Lower Palaeolithic hunting spears from Germany. Nature 1997, 385, 807.

[15] Peregrine, P. N.; Ember, M. Encyclopedia of Prehistory. Volume 1: Africa. In Springer Science \& Business Media: 2001.

[16] Clark, J. D. The Cambridge history of Africa. Vol.1, From the earliest times to c.500 BC. Cambridge University Press: Cambridge, 1982.

[17] Fage, J. D. The Cambridge history of Africa. Vol.2 : from c.500 BC to $A D$ 1050. Cambridge University Press: Cambridge, 1978.

[18] Slon, V.; Viola, B.; Renaud, G.; Gansauge, M.-T.; Benazzi, S.; Sawyer, S.; Hublin, J.-J.; Shunkov, M. V.; Derevianko, A. P.; Kelso, J.; Prüfer, K.; Meyer, M.; Pääbo, S. A fourth Denisovan individual. Science Advances 2017, 3.

[19] Brown, S.; Higham, T.; Slon, V.; Pääbo, S.; Meyer, M.; Douka, K.; Brock, F.; Comeskey, D.; Procopio, N.; Shunkov, M.; Derevianko, A.; Buckley, M. Identification of a new hominin bone from Denisova Cave, Siberia using collagen fingerprinting and mitochondrial DNA analysis. 2016, 6, 23559.

[20] Racimo, F.; Gokhman, D.; Fumagalli, M.; Ko, A.; Hansen, T.; Moltke, I.; Albrechtsen, A.; Carmel, L.; Huerta-Sánchez, E.; Nielsen, R. Archaic Adaptive Introgression in TBX15/WARS2. Molecular Biology and Evolution 2017, 34, 509-524.

[21] Hershkovitz, I.; Weber, G. W.; Quam, R.; Duval, M.; Grün, R.; Kinsley, L.; Ayalon, A.; Bar-Matthews, M.; Valladas, H.; Mercier, N.; Arsuaga, J. L.; Martinón-Torres, M.; Bermúdez de Castro, J. M.; Fornai, C.; Martín-Francés, L.; Sarig, R.; May, H.; Krenn, V. A.; Slon, V.; Rodríguez, L.; García, R.; Lorenzo, C.; Carretero, J. M.; Frumkin, A.; Shahack-Gross, R.; Bar-Yosef Mayer, D. E.; Cui, Y.; Wu, X.; Peled, N.; Groman-Yaroslavski, I.; Weissbrod, L.; Yeshurun, R.; Tsatskin, A.; Zaidner, Y.; Weinstein-Evron, M. The earliest modern humans outside Africa. Science 2018, 359, 456-459.

[22] Stringer, C. Evolution: What makes a modern human. Nature 2012, 485, 33-35.

[23] Aubert, M.; Brumm, A.; Ramli, M.; Sutikna, T.; Saptomo, E. W.; Hakim, B.; Morwood, M. J.; van den Bergh, G. D.; Kinsley, L.; Dosseto, A. Pleistocene cave art from Sulawesi, Indonesia. Nature 2014, 514, 223.

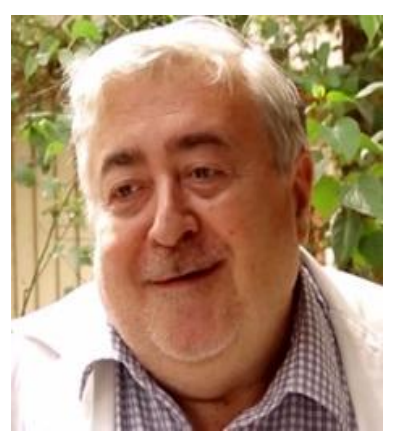

Juan Sebastián Gómez-Jeria, PhD. Graduate in Chemistry and Chemist at the University of Chile, PhD in Molecular Physical Chemistry (UNAB). Research in Quantitative Structure-Activity relationships, electronic structure of nanostructures and philosophy of science. Lecturer in Quantum Chemistry and Quantum Pharmacology and History and Philosophy of Science. He has published three books and more than 160 papers. 